\title{
Antiarrhythmic mechanisms of Malbec wine and resveratrol in isolated rat heart
}

\author{
Prado $\mathrm{NJ}^{1}$, Perdicaro DJ ${ }^{1}$, Parra $\mathrm{M}^{2}$, Carrión $\mathrm{AM}^{2}$, Miatello RM ${ }^{1}$, Renna $\mathrm{NF}^{1}$, Ponce Zumino AZ ${ }^{1,2}$, Vázquez Prieto MA ${ }^{1}$ and Diez ER ${ }^{1,2 *}$ \\ ${ }^{1}$ Instituto de Medicina y Biología Experimental de Cuyo (IMBECU), Consejo Nacional de Investigaciones Científicas y Técnicas (CONICET), Mendoza, Argentina \\ ${ }^{2}$ Instituto de Fisiología, Facultad de Ciencias Médicas, Universidad Nacional de Cuyo, Mendoza, Argentina
}

\begin{abstract}
Oxidative stress during myocardial reperfusion contributes to ventricular arrhythmias onset. We aim to evaluate the antiarrhythmic effect of Malbec wine and resveratrol and compare them with the synthetic antioxidant tiron. Since alcohol use is controversial, we also assessed dealcoholized wine.

Isolated hearts from male Sprague Dawley rats were perfused with Krebs-Henseleit solution added with: Malbec wine $(5 \mathrm{ml} / \mathrm{L})$, resveratrol $(10 \mu \mathrm{M}$,$) compared$ to controls with alcohol $(0.5 \mathrm{ml} / \mathrm{L})$; dealcoholized wine $(5 \mathrm{ml} / \mathrm{L})$, tiron $(10 \mathrm{mM})$ were compared with controls without alcohol. Epicardial action potentials were analyzed during basal state, regional ischemia and reperfusion (10 minutes each period). The incidence of arrhythmias was determined. The antioxidant effect was assessed in left ventricle homogenates and expressed as a percentage of inhibition of the ABTS•+ radical.
\end{abstract}

Malbec wine and resveratrol reduced reperfusion arrhythmias in 56\% and 50\%, respectively, compared to $100 \%$ incidence in the control group with alcohol.

Dealcoholized wine reduced arrhythmias to 50\% compared to non-alcoholic control (90.5\%), but tiron did not protect (69\%). The free radicals inhibitory effect increased with all the compounds (resveratrol 54.2\%, tiron 43.2\%, Malbec wine 42.9\%, dealcoholized wine 40.2\%) with respect to the control groups (with alcohol 23.5\%, without alcohol 21.2\%). Resveratrol shortened action potential duration and prevented ischemic depolarization. Malbec prevented ischemic-induced action potential shortening.

We conclude that Malbec wine and resveratrol are antiarrhythmic beyond their antioxidant properties. Alcohol content or was not essential. Protection from ischemic action potential changes could be relevant to the antiarrhythmic effect of both resveratrol and wine.

\section{Introduction}

Acute ischemic events are emergencies relevant for every physician [1]. The best and earliest treatment for myocardial ischemia is reperfusion [2]. However, during reperfusion, oxidative stress and metabolic/electrolyte imbalance contribute to ventricular arrhythmias onset [3]. Indeed, brief periods of ischemia and reperfusion due to coronary artery vasospasm could underlie sudden cardiac death $[4,5]$.

Antioxidants are potential therapeutic strategies against cardiovascular diseases, including reperfusion injury [6-9]. Particularly, wine attracted much attention as cardioprotective due to the so-called French paradox [10-12]. Prospective studies suggest that wine is more protective against cardiovascular diseases than other alcoholic beverages like beer or liqueur $[6,13,14]$. Alcohol addictive properties and the damage associated with abuse make the wine difficult to recommend [15]. Besides alcohol, other components in wine support its protective properties $[10,11,13,15,16]$. However, the electrophysiological effects of wine are missing.

Resveratrol is one of the most studied wine components both in vivo and in vitro $[12,17,18]$. Clinical studies support discrete cardiovascular protection only after supplementation with high doses of resveratrol [19-21]. Its antioxidant, anti- inflammatory, fibrinolytic, and anti-atherogenic effects protect the endothelial organ [22-24]. High concentration of this stilbenoid is antiarrhythmic [25-30]. At micromolar concentrations, resveratrol inhibits voltage-sensitive calcium and potassium currents and activates ATP sensitive potassium channels $\left(\mathrm{IK}_{\text {ATP }}\right)[18,25,26,29-31]$.
We aim to evaluate the electrophysiological effects (action potentials and arrhythmias) of Malbec wine and resveratrol. To clarify the role of antioxidant properties as a potential antiarrhythmic mechanism, we compared them with the synthetic antioxidant tiron [32]. Since alcohol use is mechanistically and epidemiologically controversial, we also assessed dealcoholized wine.

\section{Materials and methods}

The animals were treated according to the local Committee on Ethics of Animal Experimentation recommendations, which are in agreement with the Guide for the Care and Use of Laboratory Animals as adopted and promulgated by the US National Institutes of Health.

Male Sprague Dawley rats weighing 260 to 320 g were used. Until euthanasia, animals were housed in metal cages with food and water at libitum and exposed to a cycle of 12/12h of light/darkness, respectively. After the deep anesthetic plane was achieved (by $80 \mathrm{mg} / \mathrm{kg}$ ketamine and $5 \mathrm{mg} / \mathrm{kg}$ xylazine i. p.), the hearts were removed and mounted on

Correspondence to: Emiliano R. DIEZ, Instituto de Fisiología, Facultad de Ciencias Médicas, Universidad Nacional de Cuyo, Mendoza, Argentina. Centro Universitario. CP 5500, Mendoza. Argentina, Tel: 54-261-4135000, ext. 2763; Fax: 54-0261-4287370; E-mail: diez.emiliano@fcm.uncu.edu.ar

Key words: wine, oxidative stress, resveratrol, reperfusion injury, arrhythmia

Received: February 08, 2018; Accepted: February 20, 2018; Published: February 26, 2018 
the aortic cannula of the Langendorff perfusion setup in less than 3 min. A modified Krebs-Henseleit $(\mathrm{KH})$ perfusion solution contained $(\mathrm{mM}): 121 \mathrm{NaCl}, 5 \mathrm{KCl}, 2 \mathrm{CaCl}_{2}, 1.2 \mathrm{NaHPO}_{4}, 1.2 \mathrm{MgSO}_{4}, 25 \mathrm{NaHCO}_{3}$ and 10 glucose. The $\mathrm{pH}$ was $7,4 \pm 0,05$ when equilibrated with $5 \% \mathrm{CO}_{2}$ in $\mathrm{O}_{2}$, and temperature the perfusate was kept at $36 \pm 0.5^{\circ} \mathrm{C}$.

\section{Six experimental series were performed}

1) Control: $\mathrm{KH}$ without additional components $(\mathrm{n}=21)$;

2) De-alcoholized Malbec, $\mathrm{KH}$ plus $5 \mathrm{ml} / \mathrm{L}$ of wine dealcoholized as described below $(n=10)$;

3) tiron, $10 \mathrm{mM}$ of the sintetic antioxidant $(\mathrm{n}=13)$;

4) Malbec, $5 \mathrm{ml} / \mathrm{L}$ of wine, $(\mathrm{n}=9)$ the composition of the Malbec is described below;

5) Resveratrol, $10 \mu \mathrm{M}$ of resveratrol disolved in ethanol to final concentration of $0.5 \mathrm{ml} / \mathrm{L},(\mathrm{n}=18)$

6) Controls Alcohol, $\mathrm{KH}$ with the addition of $0.5 \mathrm{ml} / \mathrm{L}$ ethanol $(\mathrm{n}=12)$

The Facultad de CienciasAgrarias (School of Agricultural Sciences, National University of Cuyo) provided the red wine from the Malbec grape variety. The characterization by high-performance liquid chromatography of Malbec was previously published [33]. The batch of Malbec wine contained $2.9 \mathrm{~g} / \mathrm{L}$ of total phenols, $0.5 \mathrm{~g} / \mathrm{L}$ of total anthocyanins and $3.8 \mathrm{~g} / \mathrm{l}$ of total tannins. Resveratrol concentration was $1.1 \mathrm{mg} / \mathrm{L}$. The other main components were (in $\mathrm{mg} / \mathrm{L}$ ): A) nonflavonoids: 18.2 gallic acid; 2 caffeic acid; 4.2 cis- caftaric acid, B) flavonoids: 24.1 catechin; 14.2 epicatechin; procyanidin $(11.3 \mathrm{~B} 1 ; 3.1$ B3), C) flavonols: 4.9 quercetin, and D) anthocyanins: 344 malvidin3-glucoside; 16.2 peonidin-3-glucoside; 60.3 delphinidin-3-glucoside.

Malbec wine was dealcoholized by rotary evaporation at low temperature and pressure as previously described [34]. To conserve the phenolic composition, we added a volume of water according to the alcohol evaporated.

Although resveratrol was not the most abundant phenolic component in the wine, we decided to use it as the comparator because resveratrol is the best electrophysiologically characterized. The concentration used in this study is also in agreement with previous publication showing its cardioprotective properties [25-30]. Unless specified, all the other reagents were from Sigma-Aldrich (Saint Louis MO, USA).

After 20 min of equilibration, action potential and ECG were recorded during three periods of 10 minutes: basal state, ischemia (by anterior descending coronary artery occlusion with a $6 / 0$ silk thread), and reperfusion. Ischemia and reperfusion were efficiently confirmed by coronary flow measurements. A reduction of $25 \%$ or more, after occlusion was corroborated in all the hearts.

Transmembrane potential was recorded glass microelectrodes (filled with $3 \mathrm{M} \mathrm{KCl}$ ) from epicardial ventricular cells and synchronously displayed with the electrocardiogram (ECG), obtained with a positive electrode in the apex and the negative close the right atria. Microelectrodes (10 to $15 \mathrm{M} \Omega$ resistances) were amplified five times with custom-made equipment. Both signals were photographed from the screen of the oscilloscope (Tektronix 565) with a C4 Grass camera. The following action potential characteristics were measured: resting membrane potential (RMP), action potential amplitude (APA), and action potential duration at $90 \%$ of repolarization $\left(\mathrm{APD}_{90}\right)$. The heart rate was measured from the ECG and the cell recordings. Arrhythmias were classified according to the Lambeth conventions [35]. A severity score of the arrhythmias was determined every minute. The values of the scale were: 0 sinus rhythm, 1 premature ventricular beats or bigeminy, 2 Salvos, 3 nonsustained ventricular tachycardia $(<30 \mathrm{~s}), 4$ sustained ventricular tachycardia $(>30 \mathrm{~s})$, and 5 ventricular fibrillations. The hearts included in this study did not present sustained arrhythmias before reperfusion.

After of reperfusion, samples of $10 \mathrm{mg}$ from the left ventricle free wall were transferred to Eppendorf tubes containing phosphate buffered saline, $\mathrm{pH} 7.4$, and stored at $-75^{\circ} \mathrm{C}$. All samples were homogenized keeping the temperature low by immersion of the tubes in ice during the process. The total antioxidant capacity was determined as previously described $[36,37]$. In brief, the radical ABTS •+, monocation of 2,29-azinobis-(3- ethylbenzothiazoline-6-sulfonic acid) is generated by ABTS oxidation with potassium persulfate and read at $600 \mathrm{~nm}$ with a UV-visible Spectrometer (Helios Gama, Helios Delta, Unicam instruments, UK), In the presence of hydrogen-donating antioxidants the cation is reduced and the color inhibited. The changes in the color induced by the samples were measured after $18 \mathrm{~min}$ of incubation at $37^{\circ} \mathrm{C}$. The results are expressed as ABTS ++ radical inhibition in percentage.

Data are expressed as means \pm SEM. The results were analyzed with two-way ANOVA followed by the Student Newman Keuls posttest. The incidence of arrhythmias was tested with contingency tables using the Fisher exact test. The statistical level of significance was $\mathrm{P}<0.05$.

\section{Results}

\section{Arrhythmias}

Brief ventricular tachycardia developed during the first seconds of flow restitution in control group regardless the presence of alcohol. One example of this arrhythmias is shown in Figure 1. In both control groups (with and without alcohol), the tachycardia persisted during reperfusion and alternated with episodes of ventricular fibrillation. The severity score of arrhythmias persisted high through the ten minutes evaluated (Figure 2).

Malbec wine prevented the onset of reperfusion arrhythmias (Figures 1 and 2). However, when arrhythmias developed in wine treated hearts, the severity persisted high like in the controls. Therefore, the severity score reflects the combination of hearts in sinus rhythm and hearts with sustained arrhythmias.

Resveratrol antiarrhythmic effect was like the one observed with Malbec wine. The hearts that suffered arrhythmias recovered sinus rhythm in less than 60 seconds. At the end of the ten minutes of reperfusion, the proportion of hearts without arrhythmias was the same that the Malbec group.

The synthetic antioxidant tiron did not reduce ventricular arrhythmias. Ventricular fibrillation developed during the first minute of reperfusion in most of the hearts and persisted during the following ten minutes.

Dealcoholized wine was as protective as Malbec and resveratrol. The preventive action was present in half of the hearts and persisted through the reperfusion period.

\section{Action potentials}

The morphology of action potentials during the different phases of the experiment showed the same pattern for both control groups (Figure 3). Therefore, we decided to show representative traces from the control with alcohol group to compare them with Malbec and resveratrol- 


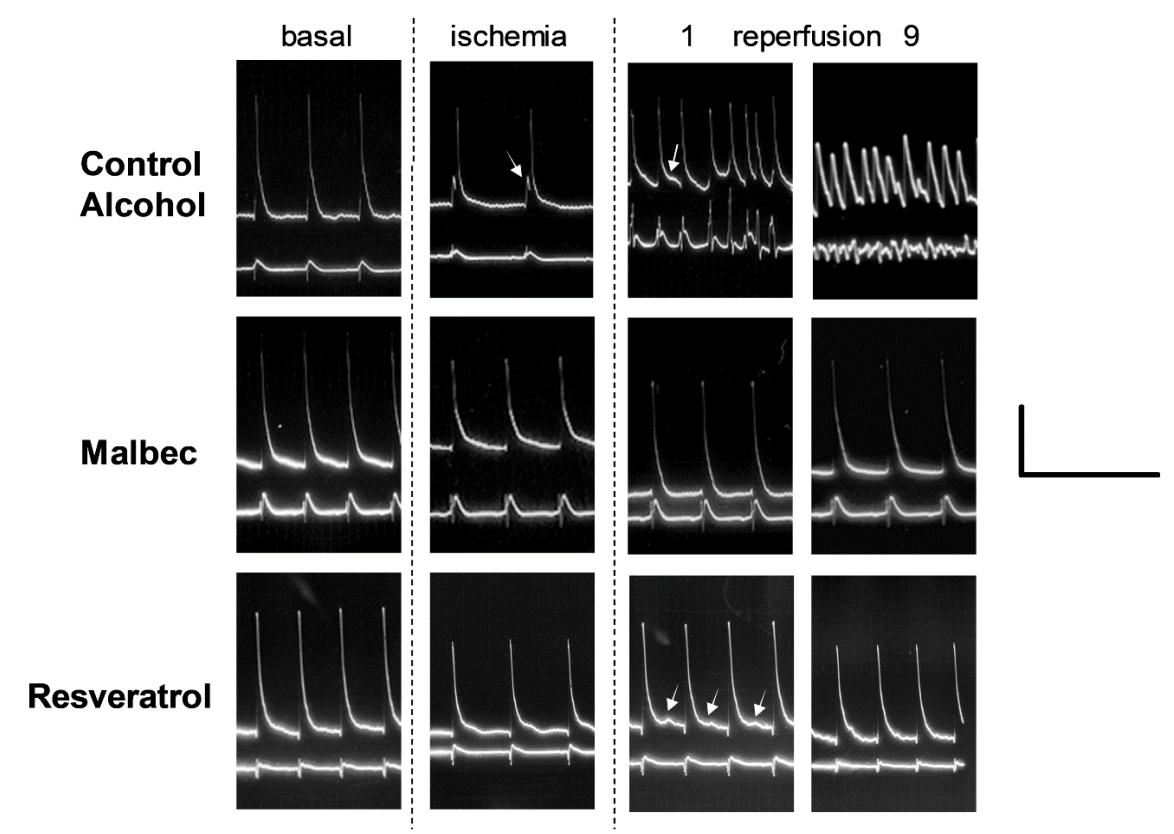

Figure 1. Representative action potentials and ECG from Control Alcohol, Malbec and Resveratrol groups. The columns indicate the experimental period; 1 and 9 correspond to the minute of reperfusion. The horizontal scale on the right corresponds to 0.5 seconds and the vertical scale correspond to $40 \mathrm{mV}$ for action potentials and to $2 \mathrm{mV}$ for ECG signal. Arrow in Control Alcohol during ischemia indicates the delay in activation and during reperfusion, the oscillation of membrane potential without reaching a resting state. Arrows during Resveratrol reperfusion indicate delay after depolarizations.
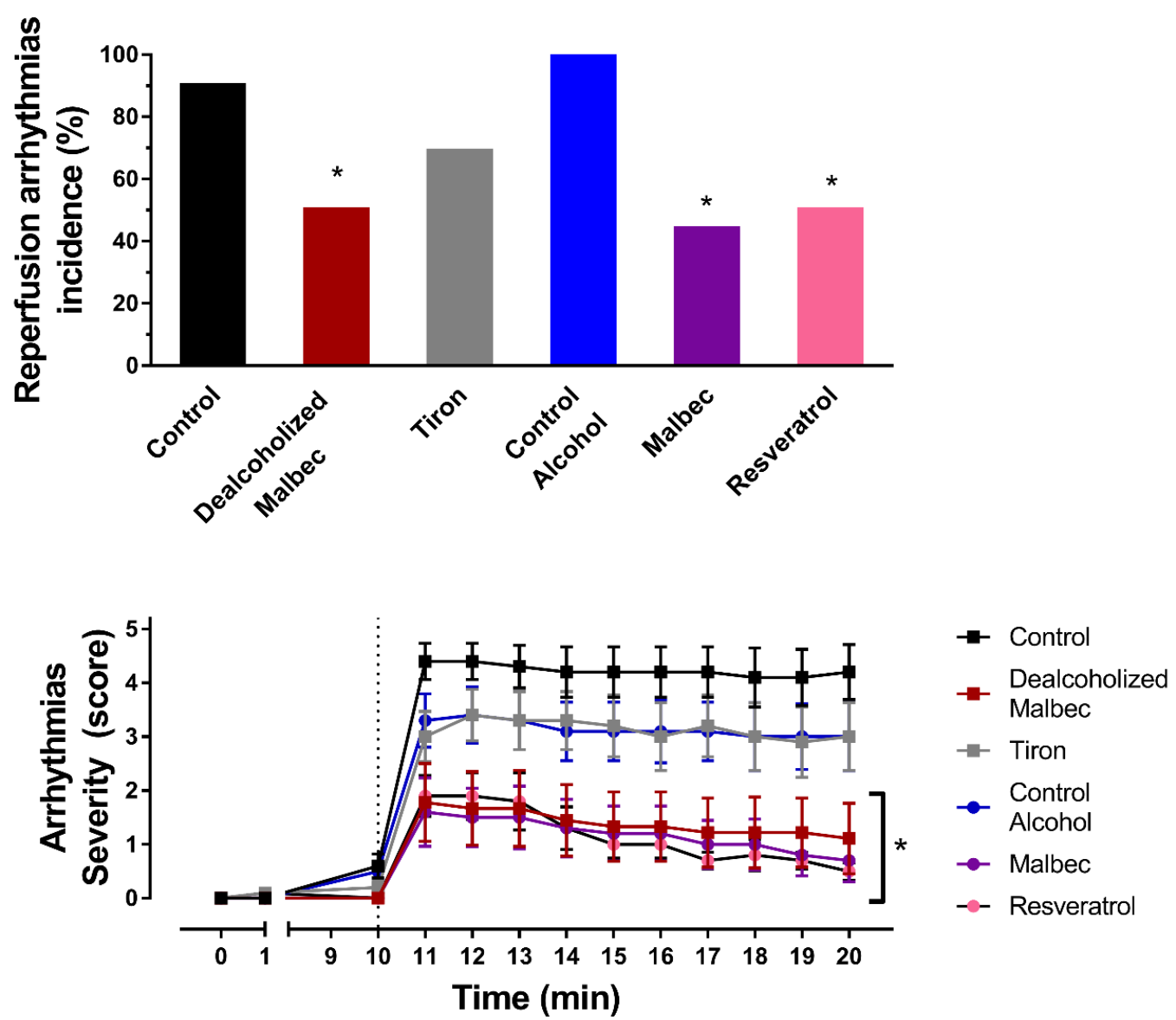

Figure 2. Reperfusion arrhythmias. Above is quantified the combined incidence of ventricular tachycardia and fibrillation Below is depicted the arrhythmic score observed minute-by-minute during reperfusion. $* \mathrm{P}<0.05$ versus the corresponding control (either with or without alcohol). 

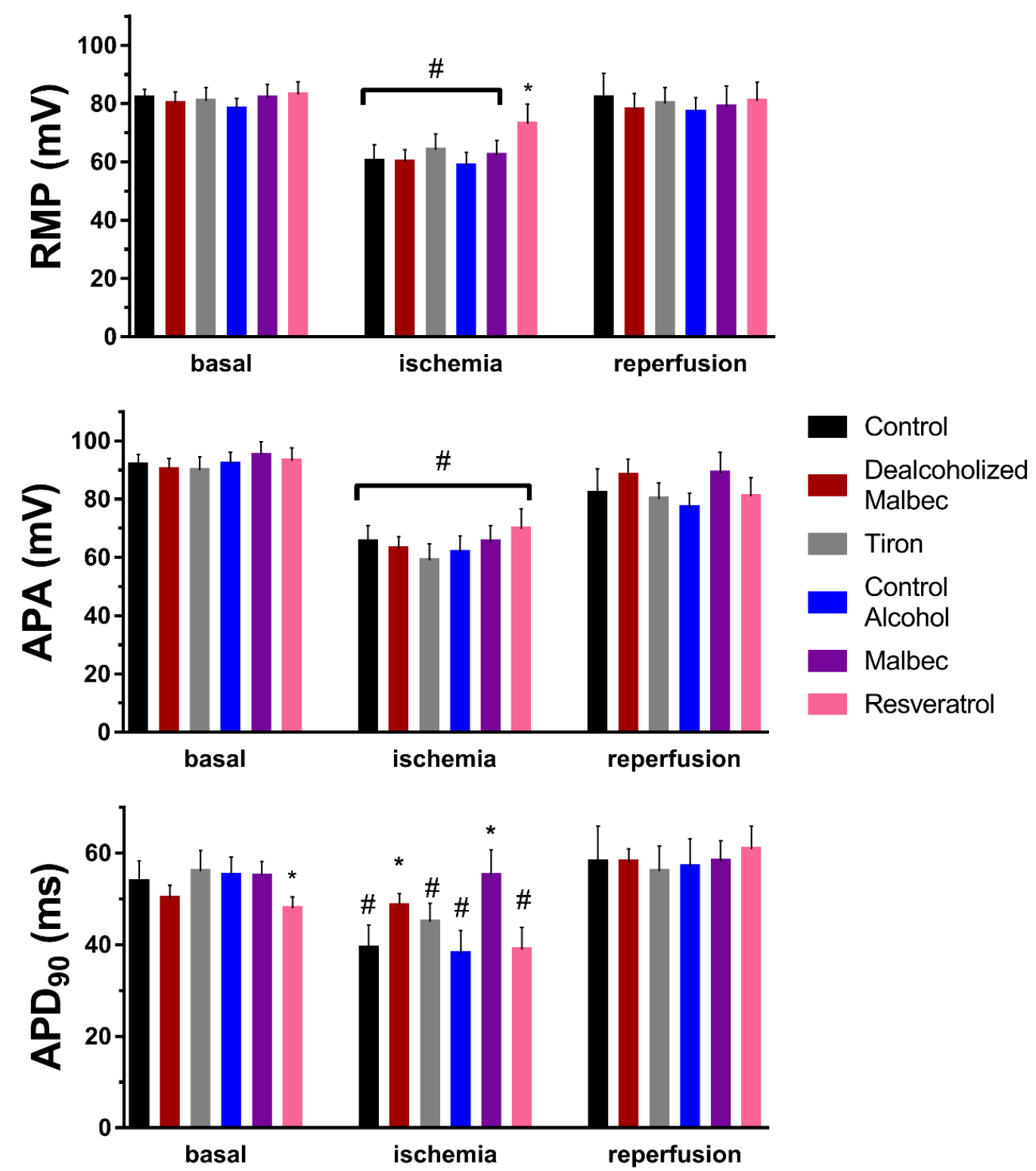

Figure 3. Action potential variables during the three experimental periods. Resting membrane potential (RMP), action potential amplitude (APA) and action potential duration measured at $90 \%$ of the repolarization $\left(\mathrm{APD}_{90}\right) . * \mathrm{P}<0.05$ versus the corresponding control (either with or without alcohol), \# $\mathrm{P}<0.05$ versus basal state values for the same group.

treated hearts (Figure 1). During the basal state, resveratrol shortened action potential duration during basal state, but resting potential and amplitude remained unchanged concerning Control. Malbec, tiron, and dealcoholized wine did not change the resting membrane potential, action potential amplitude, or duration of basal state recordings.

Action potentials from control hearts during ischemia showed resting membrane depolarization, an activation delay before the steepened depolarization (indicated by the arrow), a reduction of the amplitude and a shortening in action potential duration (Figure 1). Malbec wine with and without alcohol prevented the action potential shortening induced by ischemia (Figures 1 and 3). Resveratrol was the only treatment that preserved the resting potential during ischemia. Tiron did not modify the action potentials during ischemia.

During reperfusion, the number of action potentials to evaluated was reduced due to the presence of irregular rhythms, as can be seen in
Figure 1. The membrane oscillation could be named afterdepolarizations, but the resting potential was not clear in many cases. Therefore, the values in Figure 3 only corresponds to action potentials of beats in sinus rhythm confirmed in the ECG signal.

Interestingly, resveratrol showed delay after depolarization during the first minutes of reperfusion (see arrows in Figure 1), but the lower resting potential probably prevented the membrane from reaching the threshold to start a new action potential.

In tiron hearts that were in sinus rhythm during reperfusion, the action potentials recovered to the values observed during the basal state.

\section{Antioxidant}

The addition of alcohol to the KH solution did not increase the antioxidant capacity of the ventricles (Figure 4). Tiron and dealcoholized 
Table 1. Heart rate and coronary flow in the isolated rat heart subjected to regional ischemia and reperfusion.

\begin{tabular}{|c|c|c|c|c|}
\hline \multicolumn{3}{|c|}{ Heart rate (beats/min) } & \\
\hline Group & Before ligation & Before reperfusion & Before ligation & During ligation \\
\hline Control & $275.7 \pm 12.5$ & $239.7 \pm 10.4 \#$ & $15.0 \pm 1.4$ & $7.4 \pm 1.4 \#$ \\
\hline Dealcoholized Malbec & $290.7 \pm 13.0$ & $223.5 \pm 10.2 \#$ & $13.6 \pm 0.8$ & $6.9 \pm 0.9 \#$ \\
\hline Tiron & $279.2 \pm 14.4$ & $236.7 \pm 11.9 \#$ & $14.9 \pm 1.5$ & $7.5 \pm 0.8 \#$ \\
\hline Control Alcohol & $270.7 \pm 12.0$ & $256.7 \pm 11.9 \#$ & $17.6 \pm 1.6$ & $9.4 \pm 0.9 \#$ \\
\hline Malbec & $291.2 \pm 12.8$ & $256.7 \pm 11.9 \#$ & $13.4 \pm 1.5$ & $7.0 \pm 1.2 \#$ \\
\hline Resveratrol & $298.1 \pm 12.1$ & $231.8 \pm 12.4 \#$ & $1.8 \pm 1.9$ & \\
\hline
\end{tabular}

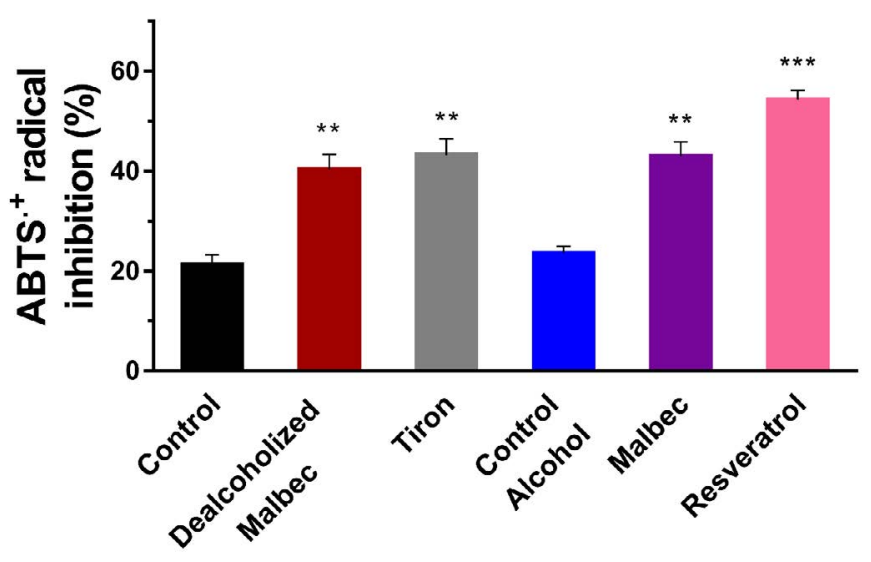

Figure 4. Antioxidant effect of ventricular homogenates measured as percentage of inhibition of the ABTS $\bullet+$ radical. $* * \mathrm{P}<0.01$ and $* * * \mathrm{P}<0.001$ versus the corresponding control (either with or without alcohol).

Malbec increased the antioxidant power in the myocardial tissue when compared to the control group. Malbec also increased the antioxidant capacity respect to both control and control with alcohol groups. The most effective antioxidant in this study was resveratrol.

\section{Heart rate and coronary flow}

Heart rate was the same in all groups before ischemia (Table 1). During ischemia, heart rate decreases around 20 to 50 beats $/ \mathrm{min}$ in all hearts. Values of heart rate from reperfusion are not shown due to big disparities caused by arrhythmias.

The coronary flow remained stable in all the hearts without difference between the treatments (Table 1). After coronary ligation, the flow decreased 30 to $50 \%$ in all cases. Reversibility of this reduction confirmed that reperfusion was successfully achieved.

\section{Discussion}

This study describes antiarrhythmic properties of Malbec wine and confirms resveratrol ones [25-30]. The electrophysiological mechanisms were different between them. During ischemia, Malbec prevented action potential shortening, and resveratrol prevented resting depolarization. Out results with dealcoholized wine refute any contribution or interference of alcohol to wine electrophysiological effects. The lack of effect of antioxidant tiron questions the role of free radicals as the primary determinant of reperfusion arrhythmias.

To our knowledge, this is the first report of the direct antiarrhythmic effect of Malbec wine (both with and without alcohol). Epidemiological studies suggested that red wine consumption is associated with a reduction of mortality and morbidity from ischemic heart disease, but there is no direct evidence to support wine as antiarrhythmic $[6,11,15,16,18]$. The antiarrhythmic mechanisms of natural drugs are usually deductions based on physiopathological reasoning, in vitro determinations and theoretical conclusions [38]. Here we demonstrate action potential modification by wine as a plausible explanation for its antiarrhythmic action after ischemia/reperfusion in rat hearts. Since the changes observed with wine occurred during ischemia, further electrophysiological characterization by techniques like path clamp will be difficult. Reproducibility is a potential problem because wine composition changes over time due to the varietals and vinification [39-41]. Our results interpretation should be taken with caution because they were obtained in isolated hearts, without autonomous nervous system or hemodynamic stress. The translation to human arrhythmias is unknown, but rat and human electrophysiology are markedly different [42-44].

The electrophysiological characteristics of Malbec and resveratrol in ventricular myocytes may play an important role in its antiarrhythmic effects beyond its antioxidant and free radical scavenging actions. Tiron was as antioxidant as Malbec but failed to protect from arrhythmias or modified action potentials. The preventive effect of Malbec against action potential shortening during ischemia could homogenize repolarization and reduce the substrate for reentrance [45-47]. We have previous results that support the protective role of antiischemic modification with melatonin (also a wine constituent) [37,48]. Besides, the activation was not delayed (compare the delay indicated by the arrows in control hearts from Figure 1) during ischemia suggesting that conduction could be preserved. Resveratrol also preserved conduction during ischemia, but the main change observed was relative hyperpolarization. This could be attributed to the reported activation of IK ${ }_{\text {ATP }}$ channels [26,27,31,49-51]. During ischemia, this channel open do to ATP/ADP imbalance, oxidative stress and acidosis [46,52-54]. Indeed, hyperpolarization could counteract triggered arrhythmias originated from delay after depolarizations, because the membrane threshold is more difficult to reach.

Despite the beneficial effects of doses of red wine, it is a health risk due to liver damage and physical addiction $[11,15]$. The antiarrhythmic effect of dealcoholized wine could overcome the problems mentioned above. We have previously reported protective effects of dealcoholized red wine against vascular remodeling and metabolic syndrome [34]. Our results support the nutraceutical properties of dealcoholized wine [11]. Another non-alcoholic derivate from grapes, like pomace, also possesses cardioprotective potential [55].

We could not attribute our results to any specific component of wine. For example, resveratrol content of Malbec was one thousand times lower than the one in Resveratrol group [12,20,21,56]. Also, most of the electrophysiological properties describe until now were obtained above the micromolar concentration range of resveratrol [25-30]. These concentrations are impossible to be achieved by Malbec or any red wine consumption alone $[12,33]$. Catechin, melatonin, and quercetin are also wine components, but the effective concentrations are at least two orders of magnitude below the active electrophysiological levels $[7,12,36,57-59]$. 
We conclude that Malbec wine is an antiarrhythmic as effective as resveratrol, beyond its antioxidant properties and unrelated to alcohol content. Protection from ischemic action potential shortening could be a relevant contributor to the antiarrhythmic effect of wine.

\section{Funding}

I+D+i 2015 Universidad Nacional de Cuyo and PICT-2014-0547.

\section{References}

1. Moens AL, Claeys MJ, Timmermans JP, Vrints CJ (2005) Myocardial ischemia/ reperfusion-injury, a clinical view on a complex pathophysiological process. Int $J$ Cardiol 100: 179-190. [Crossref]

2. Al'Aref SJ, Wong SC, Swaminathan RV, McNair P, Feldman DN, et al. (2017) Analysis of reperfusion time trends in patients with ST-elevation myocardial infarction across New York State from 2004 to 2012. Int J Cardiol 232: 140-146. [Crossref]

3. Mehta RH, Yu J, Piccini JP, Tcheng JE, Farkouh ME, et al. (2012) Prognostic significance of postprocedural sustained ventricular tachycardia or fibrillation in patients undergoing primary percutaneous coronary intervention (from the HORIZONS-AMI Trial). Am J Cardiol 109: 805-812. [Crossref]

4. Mishra PK (2006) Variations in presentation and various options in management of variant angina. Eur J Cardiothorac Surg.29: 748-759.

5. Caiati C, Erminio Lepera M, Marzullo A, Favale S. (2016) Sudden cardiac death in a woman with clinical evidence of coronary vasospastic disease and myocardial stunning. A necrospy insight into the etiology. Cardiovasc. Disord.

6. Rakotovao A, Berthonneche C, Guiraud A, de Lorgeril M, Salen P (2004) Ethanol, Wine, and Experimental Cardioprotection in Ischemia/Reperfusion: Role of the Prooxidant/Antioxidant Balance. Antioxid. Redox Signal. 6: 431-438. [Crossref]

7. Ikizler M, Erkasap N, Dernek S, Kural T, Kaygisiz Z (2007) Dietary polyphenol quercetin protects rat hearts during reperfusion: enhanced antioxidant capacity with chronic treatment.Anadolu Kardiyol. Derg 7: 404-410. [Crossref]

8. Ekeløf S, Jensen SE, Rosenberg J, Gögenur I (2014) Reduced Oxidative Stress in STEMI Patients Treated by Primary Percutaneous Coronary Intervention and with Antioxidant Therapy: A Systematic Review. Cardiovasc Drugs Ther 28: 173-181[Crossref]

9. Steare SE, Yellon DM (1995) The potential for endogenous myocardial antioxidants to protect the mycocardium against ischaemia-reperfusion injury: Refreshing the parts exogenous antioxidants cannot reach? J Mol Cell Cardiol 27: 65-74. [Crossref]

10. Vazquez-Prieto MA, Renna NF, Diez ER, Cacciamani V, Lembo C, et al. (2011) Effect of red wine on adipocytokine expression and vascular alterations in fructose-fed rats. Am J Hypertens 24: 234-240. [Crossref]

11. Sara Arranz, Gemma Chiva-Blanch, Palmira Valderas-Martínez, Alex Medina Remón, Rosa M. Lamuela-Raventós, et al. (2014) Wine, alcohol, polyphenols and cardiovascular disease. Nutr Aging 2: 101-109. [Crossref]

12. Fernández-Mar MI, Mateos R, García-Parrilla MC, Puertas B, Cantos- Villar E (2012) Bioactive compounds in wine: Resveratrol, hydroxytyrosol and melatonin: A review. Food Chem 130: 797-813.

13. Klatsky AL (2010) Alcohol and cardiovascular health. Physiol Behav 100: 76-81 [Crossref]

14. Hung CL, Lai YJ, Chi PC, Chen LC, Tseng YM et al, (2018) Dose-related ethanol intake, $\mathrm{Cx} 43$ and Nav1.5 remodeling: Exploring insights of altered ventricular conduction and QRS fragmentation in excessive alcohol users. J Mol Cell Cardiol 114: 150- 160. [Crossref]

15. Haseeb S, Alexander B, Baranchuk A (2017) Wine and Cardiovascular Health: A Comprehensive Review. Circulation 136: 1434-1448. [Crossref]

16. Lorgeril M de, Salen P, Martin JL, Boucher F, Paillard F, Leiris J. de (2002) Wine drinking and risks of cardiovascular complications after recent acute myocardial infarction. Circulation 106:1465-1469.

17. Fogacci F, Tocci G, Presta V, Fratter A, Borghi C, et al. (2018) Effect of resveratrol on blood pressure: A systematic review and meta-analysis of randomized, controlled, clinical trials. Crit Rev Food Sci Nutr.1-14. [Crossref]

18. Stephan LS, Almeida ED, Markoski MM, Garavaglia J, Marcadenti A (2017) Red Wine, Resveratrol and Atrial Fibrillation. Nutrients. 9: 1190. [Crossref]

19. Carrizzo A, Forte M, Damato A, Trimarco V, Salzano F, et al. (2013) Antioxidant effects of resveratrol in cardiovascular, cerebral and metabolic diseases. Food Chem. Toxicol 61:215-226. [Crossref]
20. Brown L, Kroon PA, Das DK, Das S, Tosaki A, et al. (2009) The biological responses to resveratrol and other polyphenols from alcoholic beverages, Alcohol. Clin Exp Res. 33: 1513-1523. [Crossref]

21. Neves AR, Lucio M, Lima JL, Reis S. (2012) Resveratrol in Medicinal Chemistry: A Critical Review of its Pharmacokinetics, Drug-Delivery, and Membrane Interactions, Curr Med Chem 19: 1663-1681. [Crossref]

22. Miatello R, Vázquez M, Renna N, Cruzado M, Zumino AP (2005) Chronic administration of resveratrol prevents biochemical cardiovascular changes in fructosefed rats. Am J Hypertens 18: 864-870. [Crossref]

23. Bonnefont-Rousselot D (2016) Resveratrol and cardiovascular diseases. Nutrients. 8.[Crossref]

24. Li H Förstermann U (2009) Resveratrol: A multifunctional compound improving endothelial function: Editorial to: "Resveratrol supplementation gender independently improves endothelial reactivity and suppresses superoxide production in healthy rats" by S. Soylemez et al. Cardiovasc Drugs Ther 23: 425-429. [Crossref]

25. Chen WP, Su MJ, Hung LM (2007) In vitro electrophysiological mechanisms for antiarrhythmic efficacy of resveratrol, a red wine antioxidant. Eur J Pharmacol 554:196-204. [Crossref]

26. Protić D, Beleslin-Čokić B, Spremović-Rađenović S, Radunović N, Heinle H, et al. (2014) The Different Effects of Resveratrol and Naringenin on Isolated Human Umbilical Vein: The Role of ATP-Sensitive K + Channels. Phyther Res 28:1412-1418. [Crossref]

27. Chen YR, Yi FF, Li XY, Wang CY, Chen L, et al. (2008) Resveratrol Attenuate Ventricular Arrhythmias and Improves the Long- Term Survival in Rats with Myocardial Infarction. Cardiovasc. Drugs Ther 22: 479-485. [Crossref]

28. Y. Zhang, Y. Liu, T. Wang, B. Li, H. Li, Z. Wang, B. Yang (2006) Resveratrol, a natural ingredient of grape skin: Antiarrhythmic efficacy and ionic mechanisms. Biochem Biophys Res Commun 340: 1192-1199. [Crossref]

29. Chunping Qian, Jihua Ma, Peihua Zhang, Antao Luo, Chao Wang (2012) Resveratrol Attenuates the $\mathrm{Na}+$-Dependent Intracellular $\mathrm{Ca} 2+$ Overload by Inhibiting $\mathrm{H} 2 \mathrm{O} 2$ Induced Increase in Late Sodium Current in Ventricular Myocytes. PLoS One 7:e51358. [Crossref]

30. Zhang LP, Ma HJ, Zhao J, Wang QS (2005) Effects of resveratrol on delayed afterdepolarization and triggered activity induced by ouabain in guinea pig papillary muscles. Sheng Li Xue Bao 57: 361-366. [Crossref]

31. Du RH, Dai T, Cao WJ, Lu M, Ding JH (2014) Kir6.2-containing ATP- sensitive K+ channel is required for cardioprotection of resveratrol in mice. Cardiovasc. Diabetol 13:35. [Crossref]

32. Taiwo FA (2008) Mechanism of tiron as scavenger of superoxide ions and free electrons, Spectroscopy 22: 491-498.

33. Fanzone M, Peña-Neira A, Jofré V, Assof M, Zamora F (2010) Phenolic Characterization of Malbec Wines from Mendoza Province (Argentina) J Agric Food Chem 58: 2388 2397.

34. Vazquez-Prieto MA, Renna NF, Lembo C, Diez ER, Miatello RM (2010) Dealcoholized red wine reverse vascular remodeling in an experimental model of metabolic syndrome: Role of NAD(P)H oxidase and eNOS activity. Food Funct 1:124-129. [Crossref]

35. Curtis MJ1, Hancox JC, Farkas A, Wainwright CL, Stables CL, et al. (2013) The Lambeth Conventions (II): Guidelines for the study of animal and human ventricular and supraventricular arrhythmias. Pharmacol Ther 139: 213-248. [Crossref]

36. Diez ER, Renna NF, Prado NJ, Lembo C, Ponce Zumino AZ (2013) Melatonin, given at the time of reperfusion, prevents ventricular arrhythmias in isolated hearts from fructose-fed rats and spontaneously hypertensive rats. J Pineal Res 55: 166-173. [Crossref]

37. Diez ER, Prados LV, Carrión A, Ponce ZA, Miatello RM (2009) A nove electrophysiologic effect of melatonin on ischemia/reperfusion-induced arrhythmias in isolated rat hearts. J Pineal Res 46:155-160. [Crossref]

38. Li J, Hu D, Song X, Han T, Gao Y, et al. (2017) The Role of Biologically Active Ingredients from Natural Drug Treatments for Arrhythmias in Different Mechanisms. Biomed Res Int 1-10. [Crossref]

39. Cheng J, Liang C (2012) The variation of mineral profiles from grape juice to monovarietal cabernet sauvignon wine in the vinification process. J Food Process Preserv 36: 262-266.

40. Gómez E, Laencina J, Martinez A (1994) Vinification Effects on Changes in Volatile Compounds of Wine. J Food Sci 59: 406-409. 
41. Sun B, Neves AC, Fernandes TA, Fernandes AL, Mateus N, et al. (2011) Evolution of phenolic composition of red wine during vinification and storage and its contribution to wine sensory properties and antioxidant activity. J Agric Food Chem 59: 6550-6557. [Crossref]

42. Zumino AP, Baiardi G, Schanne OF, Petrich ER (1998) Petrich, Differential electrophysiologic effects of global and regional ischemia and reperfusion in perfused rat hearts. Effects of $\mathrm{Mg} 2+$ concentration. Mol Cell Biochem 186: 79-86. [Crossref]

43. Pandit SV, Clark RB, Giles WR, Demir SS (2001) A mathematical model of action potential heterogeneity in adult rat left ventricular myocytes. Biophys $J$ 81: 3029-3051. [Crossref]

44. Bébarová M, Matejovic P, Pásek M, Simurdová M, Simurda J (2005) Effect of ajmaline on action potential and ionic currents in rat ventricular myocytes. Gen Physiol Biophys 24: 311-325. [Crossref]

45. Karahaliou A, Katsouras C, Koulouras V, Nikas D, Niokou D (2008) Ventricular arrhythmias and antioxidative medication: experimental study. Hellenic J Cardiol 49: 320-328. [Crossref]

46. Brown DA, O'Rourke B (2010) Cardiac mitochondria and arrhythmias. Cardiovasc Res 88: 241-249. [Crossref]

47. Jalife J (2000) Ventricular fibrillation: mechanisms of initiation and maintenance. Annu. Rev Physiol 62: 25-50. [Crossref]

48. Egan Benova T, Szeiffova Bacova B, Viczenczova C, Diez E, Barancik M (2016) Protection of cardiac cell-to-cell coupling attenuate myocardial remodeling and proarrhythmia induced by hypertension. Physiol Res 65 [Crossref]

49. Sovari AA, Rutledge CA, Jeong EM, Dolmatova E, Arasu D, et al. (2013) Mitochondria oxidative stress, connexin 43 remodeling, and sudden arrhythmic death. Circ Arrhythmia Electrophysiol 6: 623-631. [Crossref]
50. Nakaya H (2014) Role of ATP-Sensitive K+ Channels in Cardiac Arrhythmias. $J$ Cardiovasc Pharmacol Ther 19: 237-243. [Crossref]

51. Workman AJ, MacKenzie I, Northover BJ (2001) A K(ATP) channel opener inhibited myocardial reperfusion action potential shortening and arrhythmias. Eur J Pharmacol 419:73-83. [Crossref]

52. Liu Y, Gao WD, O'Rourke B, Marban E (1996) Synergistic Modulation of ATPSensitive K+ Currents by Protein Kinase C and Adenosine. Circ Res 78: 443-454. [Crossref]

53. Quintanilla JG, Moreno J, Archondo T, Chin A, Pérez-Castellano N, et al. (2013) KATP channel opening accelerates and stabilizes rotors in a swine heart model of ventricular fibrillation. Cardiovasc Res 99: 576-585. [Crossref]

54. Montaigne D, Maréchal X, Lacroix D, Staels B (2015) From cardiac mitochondrial dysfunction to clinical arrhythmias. Int J Cardiol 184: 597-599. [Crossref]

55. Perdicaro DJ, Rodriguez Lanzi C, Fontana AR, Antoniolli A, Piccoli P, et al. (2017) Grape pomace reduced reperfusion arrhythmias in rats with a high-fat-fructose diet Food Funct 8: 3501-3509 [Crossref]

56. Catalgol B, Batirel S, Taga Y, Ozer NK (2012) Resveratrol: French paradox revisited. Front Pharmacol 3. [Crossref]

57. Wang Y, Zhang ZZ, Wu Y, Ke JJ, He XH, Wang YL (2013) Quercetin postconditioning attenuates myocardial ischemia/reperfusion injury in rats through the $\mathrm{PI} 3 \mathrm{~K} / \mathrm{Akt}$ pathway. Braz J Med Biol Res 46: 861-867. [Crossref]

58. Jin HB, Yang YB, Song YL, Zhang YC, Li YR (2012) Protective roles of quercetin in acute myocardial ischemia and reperfusion injury in rats. Mol Biol Rep 39:1100511009. [Crossref]

59. Katalinić V, Milos M, Modun D, Musić I, Boban M (2004) Antioxidant effectiveness of selected wines in comparison with (+)-catechin, Food Chem 86: 593-600.

Copyright: (C2018 Prado NJ. This is an open-access article distributed under the terms of the Creative Commons Attribution License, which permits unrestricted use, distribution, and reproduction in any medium, provided the original author and source are credited. 